\title{
expedited publication
}

Article abstract - We treated 18 clinically definite relapsing-remitting MS patients with recombinant gamma interferon in a pilot study designed to evaluate toxicity and dosage. Patients received low $(1 \mu \mathrm{g})$, intermediate $(30 \mu \mathrm{g})$, or high $(1,000 \mu \mathrm{g})$ doses of interferon by intravenous infusion twice a week for 4 weeks. Serum levels of gamma interferon were proportional to dose and no interferon was detected in CSF. Seven of the 18 patients had exacerbations during treatment, a significant increase compared with the prestudy exacerbation rate $(p<0.01)$. Exacerbations occurred in all three dosage groups and were not precipitated by fever or other dose-dependent side effects. There were significant increases in circulating monocytes bearing class II (HLA-DR) surface antigen, in the proliferative responses of peripheral blood leukocytes, and in natural killer cell activity. These results show that systemic administration of gamma interferon has pronounced effects on cellular immunity in MS and on disease activity within the CNS, suggesting that the attacks induced during treatment were immunologically mediated. Gamma interferon is unsuitable for use as a therapeutic agent in MS. Agents that specifically inhibit gamma interferon production or counteract its effects on immune cells should be investigated as candidates for experimental therapy.

NEUROLOGY 1987;37:1097-1102

\section{Treatment of multiple sclerosis with gamma interferon: Exacerbations associated with activation of the immune system}

\author{
Hillel S. Panitch, MD; Robert L. Hirsch, PhD; John Schindler, PhD; and Kenneth P. Johnson, MD
}

Clinical trials of alpha and beta interferon (IFN) have been undertaken in patients with MS because of evidence that a viral infection, an immunoregulatory defect, or both, may be implicated in disease activity. ${ }^{1-3}$ In a double-blind, placebo-controlled crossover trial of natural alpha IFN given systemically, ${ }^{4}$ the number of acute exacerbations in patients with relapsing-remitting MS was reduced, but the study was complicated by the crossover design and a marked placebo effect. Natural beta IFN administered intrathecally to 10 patients ${ }^{5}$ appeared to prevent exacerbations; however, the study lacked a placebo-treated control group. Recently, a multicenter double-blind controlled trial of intrathecal beta IFN ${ }^{6}$ confirmed the favorable results of the earlier study. The first clinical trial of recombinant IFN in MS, in which 2 million units of alpha ${ }_{2}$ IFN were given subcutaneously three times per week for 1 year, was recently completed. ${ }^{7}$ There was no therapeutic effect, possibly because the dose was too low. Other studies, using higher systemic doses of recombinant IFN, are in progress.

Gamma or immune IFN has many of the antiviral and immunoregulatory properties of other interferons ${ }^{8}$; in addition, it can activate macrophages and induce class II histocompatibility antigens on monocytes, ${ }^{9} \mathrm{en}$ dothelial cells, ${ }^{10}$ and astrocytes. ${ }^{11}$ These are properties that could stimulate an autoimmune process. On the other hand, recent reports of deficient gamma IFN pro- duction in MS patients ${ }^{12,13}$ suggested the possibility of a therapeutic trial. We therefore performed a pilot study of recombinant gamma IFN to determine toxicity and dose, and to judge whether a larger, long-term clinical trial would be feasible. The results have been partially reported elsewhere as a preliminary communication. ${ }^{14}$

Methods. Patients and treatment protocol. Eighteen patients with clinically definite relapsing-remitting MS participated. There were 3 men and 15 women ranging in age from 19 to 42 years. All patients had had at least two exacerbations in the preceding 2 years, and were in remission at the time of entry. The study was approved by the University of Maryland Human Volunteers Research Committee. Recombinant gamma IFN (Immuneron, Biogen Research, Cambridge, MA) was given in doses of 1,30 , or $1,000 \mu \mathrm{g}$, corresponding approximately to $1.5 \times 10^{4}, 4.5 \times 10^{5}$, and $1.5 \times 10^{7}$ IU of IFN, respectively. Patients were selected at random to receive the low, intermediate, or high doses twice a week for 4 weeks. One half of each dose was administered as an intravenous bolus; the remainder was given as an intravenous infusion over 2 hours. At the beginning and end of the trial, patients were scored according to the Kurtzke Expanded Disability Status Scale (EDSS), ${ }^{15}$ and the Scripps Neurological Rating Scale (NRS). ${ }^{16}$ Additional examinations were performed and scored for each exacerbation. An exacerbation was defined as the

From the Department of Neurology (Drs. Panitch, Hirsch, and Johnson), Maryland Center for Multiple Sclerosis, University of Maryland; the Veterans Administration Medical Center (Drs. Panitch and Johnson), Baltimore, MD; and the Biogen Research Corporation (Dr. Schindler), Cambridge, MA.

Supported by Biogen Research Corporation, National Institutes of Health Center Grant NS-20022, and the Veterans Administration.

Presented in part at the thirty-eighth annual meeting of the American Academy of Neurology, New Orleans, LA, April 1986.

Received January 28, 1987. Accepted for publication in final form April 23, 1987.

Address correspondence and reprint requests to Dr. Panitch, Department of Neurology, University of Maryland, 22 South Greene Street, Baltimore, MD 21201. 
occurrence of new or recurrent neurologic symptoms with objective confirmation on examination, lasting at least 48 hours, and followed by complete or partial resolution. Exacerbations were rated as mild, moderate, or severe based on NRS scores. ${ }^{4}$ After completion of treatment, the patients were followed monthly for 12 to 20 months, using the same criteria to define and rate exacerbations. Lumbar punctures were performed before treatment and 1 hour after completion of the last infusion to determine cell count, IgG, albumin, and interferon titer. IgG indexes were calculated and oligoclonal IgG bands were identified by agarose electrophoresis. Myelin basic protein (MBP) in CSF was measured by radioimmunoassay (Metpath Laboratories, Teterboro, $\mathrm{NJ}$ ).

Separation and analysis of mononuclear cells. Mononuclear cells (MNC) were separated from heparinized whole blood by gradient centrifugation on Ficoll-Paque (Pharmacia Fine Chemicals, Piscataway, $\mathrm{NJ})$. Cells were then washed twice in phosphate-buffered saline (PBS) and resuspended either in PBS with $5 \%$ heat-inactivated pooled normal human $A B$ serum for flow cytometry, or in RPMI-1640 medium (Gibco, Grand Island, NY) with $5 \%$ fetal bovine serum (FBS, Gibco), $10 \mathrm{mM}$ HEPES buffer, $1 \%$ glutamine, and 20 $\mu \mathrm{g} / \mathrm{ml}$ gentamicin (complete RPMI) for other assays. One-ml aliquots of MNC containing $1 \times 10^{6}$ cells were centrifuged in $12 \times 75-\mathrm{mm}$ plastic tubes at $400 \times \mathrm{g}$ for 5 minutes. Pellets were resuspended in $50 \mu \mathrm{l}$ of monoclonal antisera diluted in PBS to insure antibody excess. The antibodies included fluorescein-conjugated OKT3, OKT4, and OKT8 (Ortho Diagnostics, Raritan, NJ), and anti-Leu 11, anti-Leu M3 and anti-HLA-DR (Becton-Dickinson, Mountain View, CA). Activated monocytes were identified by double labeling with fluorescein-conjugated anti-Leu M3 and phycoerythrinconjugated anti-HLA-DR. After incubation for $30 \mathrm{~min}$ utes at $0{ }^{\circ} \mathrm{C}$, cells were washed in cold PBS with $5 \% \mathrm{AB}$ serum, and fixed in $1 \%$ paraformaldehyde. Five thousand cells per sample were analyzed in a Becton-Dickinson FACS IV flow cytometer.

Natural killer cell assay. K562 target cells were maintained in suspension culture in complete RPMI, and labeled with $100 \mu \mathrm{Ci} / 10^{6}$ cells of ${ }^{51} \mathrm{Cr}$ (Amersham, Arlington Heights, IL) on the day of the assay. MNC were added to the target cells in ratios of $20: 1,10: 1$, and $2: 1$ in a total volume of $0.2 \mathrm{ml}$ in triplicate wells of $96-$ well round-bottom microtiter plates, and incubated for 5 hours at $37^{\circ} \mathrm{C}$. Supernatants were harvested using a semiautomatic harvesting press (Skatron Inc., Sterling, VA). Filters containing $0.2 \mathrm{ml}$ of radioactive medium were counted in an LKB model 1282 gamma counter. Specific ${ }^{51} \mathrm{Cr}$ release was calculated as a percent of maximum counts released by treating target cells with $1 \%$ sodium dodecylsulfate. To determine whether NK cells retained or lost responsiveness to IFN during treatment of patients, the ability of gamma IFN to enhance NK activity in vitro was tested. Preliminary studies showed maximum enhancement of ${ }^{51} \mathrm{Cr}$ release when 1,500 units per $\mathrm{ml}$ of gamma IFN were added to cultures at an effector: target ratio of $20: 1$. After incubation with IFN for 18 hours at $37^{\circ} \mathrm{C}$, cells were centrifuged, washed, counted, resuspended in complete RPMI, and tested in the NK assay described above.

IFN assay and gamma IFN synthesis. Production of gamma IFN by cultured cells was assayed by incubation of $2 \times 10^{6} \mathrm{MNC}$ in $2 \mathrm{ml}$ of complete RPMI with $3 \mu \mathrm{g} / \mathrm{ml}$ of concanavalin A (Con A, Difco Laboratories, Detroit, MI) or an equivalent volume of PBS, at $37{ }^{\circ} \mathrm{C}$. After three days, supernatant fluids were collected and stored at $-70^{\circ} \mathrm{C}$. IFN assays were performed using a solid phase radioimmunoassay kit (Centocor Inc, Malvern, PA) as described previously. ${ }^{17}$ Supernatant samples were assayed for 10 of the 18 patients, representing all three dosage levels, before, during (days 3 to 17), and after IFN treatment. Serum and CSF IFN levels were determined by enzymatic immunoassay at Biogen Research Corp.

Lymphocyte proliferation. MNC were suspended in complete RPMI with addition of Con $\mathrm{A}$ at a final concentration of $3 \mu \mathrm{g} / \mathrm{ml}$, PHA (PHA-P, Difco) at $20 \mu \mathrm{g} /$ $\mathrm{ml}$, or human myelin basic protein (MBP) at $10 \mu \mathrm{g} / \mathrm{ml}$. PBS was added to control cultures. Mitogen-stimulated cultures were incubated for 3 days and MBP-stimulated cultures for 5 days in flat-bottom microtiter plates at 37 ${ }^{\circ} \mathrm{C}$ with addition of $1 \mu \mathrm{Ci}$ of ${ }^{3} \mathrm{H}$ thymidine (specific activity, $40 \mathrm{Ci} / \mathrm{mM}$; Amersham) for the final 18 hours. Cells were harvested on glass fiber filters and five replicates of each sample were counted in a Beckman LS 3100 liquid scintillation counter. Counts per minute (cpm) of unstimulated cultures were subtracted from cpm of stimulated cultures to determine specific proliferative activity $(\Delta \mathrm{cpm})$. Stimulation indexes (SI) were calculated by dividing cpm of stimulated by cpm of unstimulated cultures.

Statistical methods. Exacerbations before and during treatment were compared by chi-square analysis. Results of experiments involving multiple comparisons over time were tested for significance by an analysis of variance for repeated measures. Means of other data sets were analyzed by two-tailed $t$ test.

Results. Clinical findings. Seven of the 18 patients had exacerbations of MS during 18 patient-months of IFN treatment. This differed significantly $(p<0.01)$ from the number of exacerbations during the preceding 2 years (51 attacks in 432 patient-months). The exacerbation rate increased from 1.42 to 4.67 attacks per patient per year (figure 1). Most of the exacerbations involved recurrence of signs and symptoms that the patients had experienced previously. In the seven patients who had exacerbations during treatment, the mean interval from their last exacerbation before administration of IFN was 4.6 months (range, 1 to 12 months); in the $11 \mathrm{pa-}$ tients who did not have attacks during treatment, it was 7.2 months (range, 3 to 19 months). This difference was not statistically significant. Although the number of patients with acute attacks was greatest $(3 / 5)$ in the $1,000-\mu$ group, attacks of comparable severity occurred in patients receiving $1 \mu \mathrm{g}$ or $30 \mu \mathrm{g}$ of IFN. Recovery from exacerbations was complete in all patients, and the attack rate during 12 to 20 months of follow-up was 1.05 per year (figure 1). Neurologic dysfunction as quantitated by the EDSS and NRS scores did not increase. 


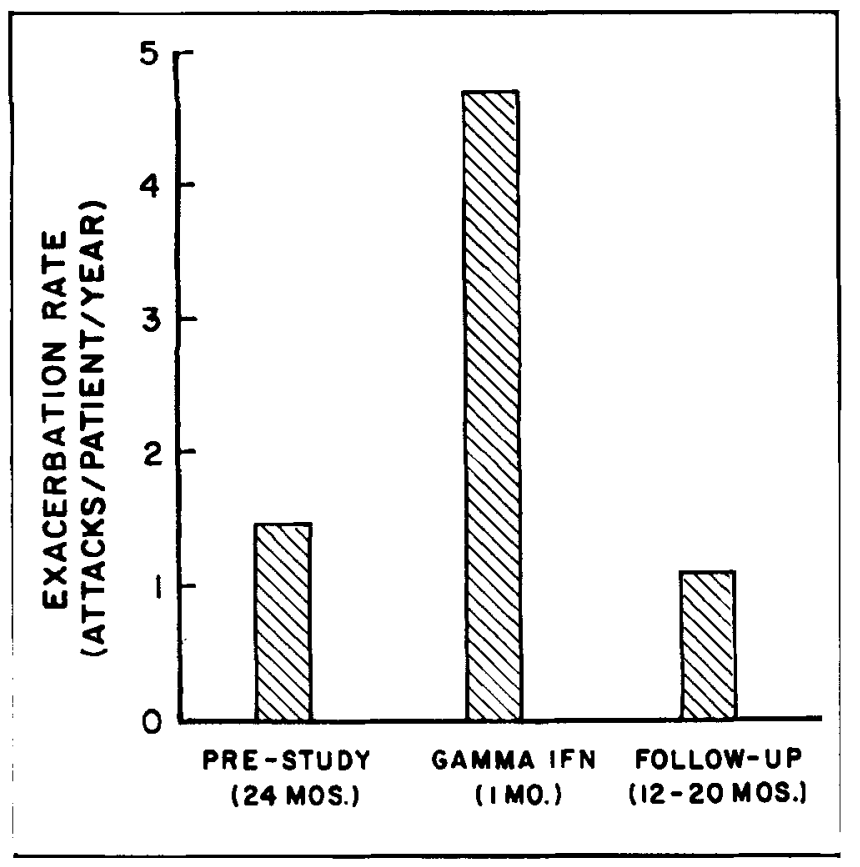

Figure 1. Increase in exacerbation rate during treatment with gamma interferon compared with pretreatment and follow-up periods.

Table 1. Side effects of systemic gamma interferon

\begin{tabular}{|lccc|}
\hline & \multicolumn{3}{c|}{ Dose } \\
\cline { 2 - 4 } Symptom & $\mathbf{1} \boldsymbol{\mu \mathbf { g }}$ & $\mathbf{3 0} \boldsymbol{\mu \mathbf { g }}$ & $\mathbf{1 , 0 0 0} \boldsymbol{\mu \mathbf { g }}$ \\
& & & \\
Fever/Chills & $1 / 6$ & $4 / 7$ & $5 / 5$ \\
Fatigue & $0 / 6$ & $3 / 7$ & $4 / 5$ \\
Myalgias/Arthralgias & $0 / 6$ & $3 / 7$ & $5 / 5$ \\
Headache & $3 / 6$ & $3 / 7$ & $4 / 5$ \\
Nausea & $0 / 6$ & $3 / 7$ & $1 / 5$ \\
Other & $2 / 6$ & $3 / 7$ & $1 / 5$ \\
& & & \\
\hline
\end{tabular}

The mean pre- and post-treatment EDSS scores were each 3.7, and mean NRS scores before and after treatment were also nearly identical (73.9 versus 72.0 ). CSF cell counts, IgG indexes, MBP levels, and oligoclonal IgG bands were not significantly affected by IFN treatment.

Interferon levels and side effects. Serum levels of gamma IFN were detected only in those patients receiving the $1,000 \mu \mathrm{g}$ dose. The mean peak titer of serial samples drawn after beginning the first infusion was $128.8 \mathrm{IU} / \mathrm{ml}$ at 2 hours. No IFN could be measured in the CSF of any subject. Systemic side effects (table 1) included fever up to $104^{\circ} \mathrm{F}$, chills, headache, fatigue, and myalgia. Symptoms generally began 3 to 4 hours after each $1,000-\mu \mathrm{g}$ infusion, lasted 6 to 8 hours, were most severe with the initial treatment, and diminished in severity with subsequent infusions. Subjects who received $30 \mu \mathrm{g}$ had symptoms only after the first few doses, and those receiving $1 \mu \mathrm{g}$ had minor symptoms or none at all. Exacerbations were not directly precipitated by fever or other side effects.

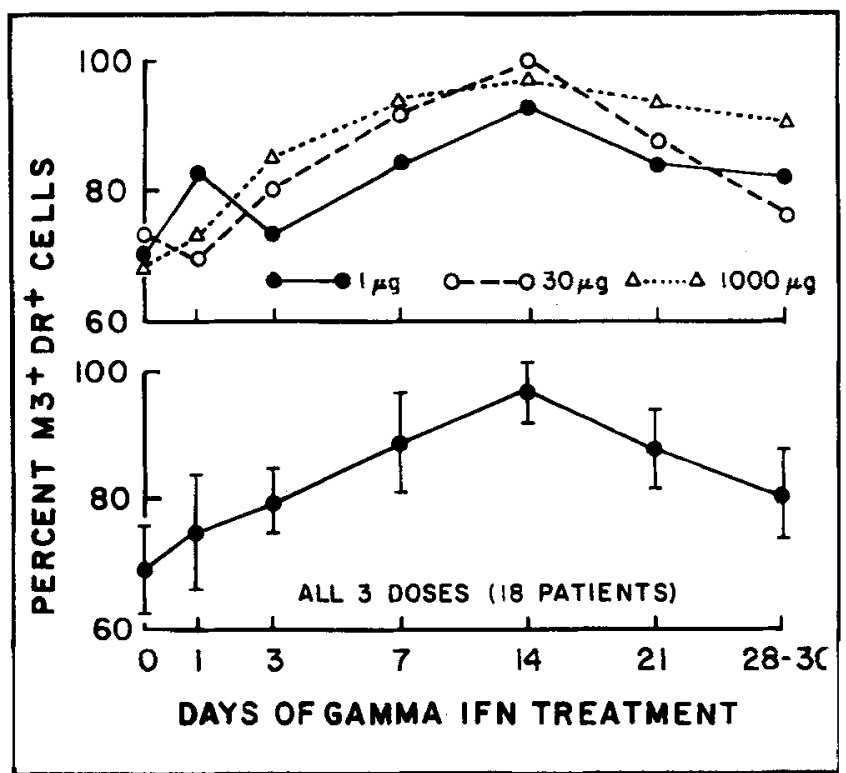

Figure 2. $\mathrm{MB}^{+} / \mathrm{HLA}-\mathrm{DR} \mathrm{R}^{+}$cells (activated monocytes) expressed as percent of $\mathrm{M}^{+}$cells in peripheral blood for each dosage group (top) and for all patients combined (bottom). The combined values (means $\pm S E$ ) were significantly increased at days 7 and $21(\mathrm{p}<0.05)$ and day $14(\mathrm{p}<0.01)$.

Analysis of MNC by flow cytometry. No significant changes were found in percentages or absolute numbers of cells reacting with OKT3, OKT4, or OKT8 monoclonal antibodies, or in T4/T8 ratios. The Leu 11 marker, specific for NK cells, increased on day 21, long after the early increase seen in functional NK activity on days 1 and 3 . The percentages of Leu $\mathrm{M}^{+}$and $\mathrm{HLA}^{-\mathrm{DR}^{+}}$cells were only slightly elevated, but cells positive for both markers by the double-labeling technique increased significantly in percentage (figure 2) and absolute number (data not shown). The increase was apparent in all three dosage groups, and in patients who had exacerbations the mean increase was greater than in patients without attacks ( $28.2 \%$ versus $14.3 \%, p$ $<0.05$ ).

Lymphocyte proliferation. There was a progressive increase in spontaneous proliferation of unstimulated MNC cultures during IFN treatment from 5,000 to $6,000 \mathrm{cpm}$ to over $15,000 \mathrm{cpm}$. This occurred in both $3-$ day and 5-day cultures, and was statistically significant at days $21(p<0.05)$ and $28(p<0.01)$. Responses to Con A and PHA of cultured MNC increased slightly during the study, with maximum proliferation for most subjects on day 21 (table 2); however, the SI did not increase significantly. In contrast, the proliferative response to MBP, which was suppressed below that of unstimulated cultures before treatment, increased in both cpm and SI, and was most pronounced in the seven patients with exacerbations (table 3). Dates of maximum response to MBP varied from day 7 to day 28 , but because all time points were not studied in all patients, it was not possible to determine whether the peak proliferative response coincided with the onset of attacks. Gamma IFN production. Peripheral blood MNC 
Although the effect of gamma IFN we observed was not the one we anticipated or desired, it was consistent with the ability of gamma IFN to augment immune responses and with the hypothesis that exacerbations of MS are mediated by an autoimmune process. It also showed that systemic treatment with gamma IFN can have a profound effect on disease activity within the CNS, even though interferons cross the intact bloodbrain barrier poorly. ${ }^{20}$ The observation that exacerbations precipitated by gamma IFN were clinically similar or identical to earlier exacerbations suggests that gamma IFN or activated cells may cross a recently damaged blood-brain barrier more readily than a normal barrier. The interval between the most recent previous attack and administration of gamma IFN was somewhat shorter in those patients who had exacerbations during treatment than in those who did not; but because of the small number of patients and the broad range of time intervals in each group, the difference was not statistically significant. This remains an intriguing topic for speculation.

During this study, NK cell activity remained at or above normal levels, enhancement of NK activity by IFN in vitro was maintained, and the ability of the patients' cells to produce gamma IFN in vitro was not suppressed. Nevertheless, disease activity increased in a significant number of treated patients. These results suggest that some of the so-called immunoregulatory defects in MS, in particular reduced IFN production and NK activity, do not bear a causal relationship to the pathogenesis of acute exacerbations. Several other measures of immunologic function similarly did not correlate with treatment or with disease activity. Analysis of $\mathrm{T} 4$ and $\mathrm{T} 8$ subsets and their ratios by monoclonal antibody surface staining has not been a reliable measure of disease activity in relapsing-remitting patients, ${ }^{21}$ and this study confirms that impression. CSF immunoglobulins are useful diagnostically in MS, and may be quantitatively reduced by certain types of treatment such as ACTH and corticosteroids, but this and previous studies $^{4,22}$ have shown that they cannot be used as disease markers in therapeutic trials. CSF MBP was not increased in any of the patients with acute exacerbations; but because the attacks were relatively mild and lumbar punctures were not done at the onset of attacks, we could draw no conclusions about MBP levels in this small sample of patients.

In addition to its antiviral, antiproliferative, and immunomodulatory functions, gamma IFN may strongly potentiate immune responses through activation of macrophages and T lymphocytes. ${ }^{8}$ All interferons can induce class I histocompatibility antigens on a variety of cell types; however, gamma IFN is unique in its ability to induce class II (Ia or HLA-DR) antigens. ${ }^{9,23}$ The presence of these determinants on monocytes and macrophages permits them to function as antigen-presenting cells in the induction or enhancement of immune responses. In addition, gamma IFN has recently been reported to induce Ia determinants on endothelial cells ${ }^{10}$ and astrocytes. ${ }^{11}$ Endothelial cell Ia antigen has been implicated in the pathogenesis of experimental allergic encephalomyelitis, ${ }^{24}$ an animal model of MS. Astrocytes ${ }^{11}$ and endothelial cells ${ }^{25} \mathrm{de}-$ velop the capacity to present MBP to T cells, a process that may play a central role in generation of an autoimmune response to $\mathrm{CNS}$ myelin. Because $\mathrm{Ia}^{+}$macrophages, endothelial cells, and astrocytes are prominent in MS plaques, ${ }^{26,27}$ gamma IFN could be intimately involved in the pathogenesis of disease activity.

Although the increased percentage of HLA-DR ${ }^{+}$ monocytes we detected in peripheral blood did not correspond exactly with the onset of exacerbations in all patients, the greatest increase occurred in the $30-\mu \mathrm{g}$ and $1,000-\mu \mathrm{g}$ dose groups, and patients who had exacerbations showed a greater increase in double-labeled cells than those who remained clinically stable. Studies of specific antigen-presenting activity of these cells were not done; however, the proliferative response of peripheral blood MNC to MBP was studied as a possible correlate of antigen-presenting activity. Increased proliferation to MBP in the face of relatively slight augmentation of the Con A and PHA responses suggests immunologic specificity for MBP. In the present study, although proliferative responses to other soluble protein antigens were not measured, the elevated response to MBP and its association with acute exacerbations are consistent with the interpretation that MBP-specific $T$ cells or other unidentified autoreactive antigenspecific $T$ cells may have been activated by gamma IFN. The progressive increase in spontaneous proliferation in control cell cultures suggests that nonspecific activation also occurred during gamma IFN treatment. Although we did not identify the proliferating cell type in this study, activated $T$ lymphocytes have been reported previously in the peripheral blood and CSF of patients with active MS. $^{28,29}$

In view of these findings, a possible role for gamma IFN in naturally occurring exacerbations of MS is suggested. Sibley et $\mathrm{a}^{30}$ have documented the frequent relationship of acute exacerbations to common viral infections. Viral infections can activate immune $T$ cells to produce gamma IFN, which may then induce a myelin-specific autoimmune response in the CNS. ${ }^{31}$ If disease activity is mediated by gamma IFN, either through induction of HLA-DR antigen or another mechanism, it is obvious that further clinical trials of gamma IFN in MS should not be attempted. Substances that neutralize gamma IFN, inhibit its production, block its receptors, or react with gamma-induced class II determinants might be considered for therapeutic study. Monoclonal anti-Ia antibodies have already shown promise in the prevention and treatment of experimental allergic encephalomyelitis. ${ }^{32}$ However, extension of these studies to humans may be hampered by the polymorphism of class II antigens, development of neutralizing antibodies to monoclonal mouse immunoglobulins, or by toxic side effects.

Alpha and beta interferons, in contrast, are relatively nontoxic human gene products. In addition to their antiviral, antiproliferative, and other immunomodulatory effects, they have been shown to counteract the Ia-inducing effect of gamma IFN in vitro, ${ }^{33}$ and may, therefore, have therapeutic value in vivo as 
gamma IFN antagonists. Because early clinical trials of natural alpha ${ }^{4}$ and beta ${ }^{5,6}$ interferons in MS have been promising, they should be investigated further with appropriate pilot studies to determine maximum tolerated doses and optimum frequency of administration. In view of the ability of gamma IFN to activate MS via the systemic route, it is likely that agents that counteract gamma IFN could be given systemically, and that intrathecal or intraventricular administration, which are cumbersome and potentially hazardous, can be avoided. In the conduct of such clinical trials, gamma IFN production and activity should be monitored as correlates of disease activity and immunotherapeutic effect.

\section{Acknowledgments}

We thank Sue Haley, RN, and Eleanor Katz, RN, for assistance in the clinic, Norman Karasanyi for his technical expertise, James Gardner, MS, for statistical analysis, and Regina Flynn for preparation of the manuscript.

\section{References}

1. McFarlin DE, McFarland HF. Multiple sclerosis. N Engl J Med 1982;307:1246-1251.

2. Oger J, Roos R, Antel JP. Immunology of multiple sclerosis. In: Antel JP, ed. Neurologic clinics. Philadelphia: WB Saunders, 1983:655-679.

3. Waksman BH, Reynolds WE. Multiple sclerosis as a disease of immune regulation. Proc Soc Exp Biol Med 1984;175:282-294.

4. Knobler RL, Panitch HS, Braheny SL, et al. Systemic alpha interferon therapy of multiple sclerosis. Neurology 1984;34:1273-1279.

5. Jacobs L, O'Malley J, Freeman A, Ekes R. Intrathecal interferon reduces exacerbations of multiple sclerosis. Science 1981;214:1026-1028.

6. Jacobs L, Salazar AM, Herndon R, et al. Multicentre double-blind study of effect of intrathecally administered natural human fibroblast interferon on exacerbations of multiple sclerosis. Lancet 1986;2:1411-1413.

7. Camenga DL, Johnson KP, Alter M, et al. Systemic recombinant alpha-2 interferon therapy in relapsing multiple sclerosis. Arch Neurol 1986;43:1239-1246.

8. Vilcek J, Gray PW, Rinderknecht E, Sevastopoulos CG. Interferon-gamma: a lymphokine for all seasons. In: Pick E, ed. Lymphokines, vol 11. New York: Academic Press, 1985:1-32.

9. Basham TY, Merigan TC. Recombinant interferon-gamma increases HLA-DR synthesis and expression. J Immunol $1983 ; 130: 1492-1494$.

10. Pober JS, Gimbone MA, Cotran RS, et al. Ia expression by vascular endothelium is inducible by activated $T$ cells and by human interferon. J Exp Med 1983;157:1339-1353.

11. Fierz W, Endler B, Reske K, Wekerle H, Fontana A. Astrocytes as antigen-presenting cells, I. Induction of Ia antigen expression on astrocytes by $T$ cells via immune interferon and its effect on antigen presentation. J Immunol 1985;134:3785-3793.

12. Neighbour PA, Miller AE, Bloom BR. Interferon responses of leukocytes in multiple sclerosis. Neurology 1981;31:561-566.
13. Vervliet $G$, Claeys $H$, VanHaver $H$, et al. Interferon production and natural killer cell (NK) activity in leukocyte cultures from multiple sclerosis patients. J Neurol Sci 1983;60:137-150.

14. Panitch HS, Hirsch RL, Haley AS, Johnson KP. Exacerbations of multiple sclerosis in patients treated with gamma interferon. Lancet 1987;1:893-895.

15. Kurtzke JF. Rating neurologic impairment in multiple sclerosis: an expanded disability status scale (EDSS). Neurology $1983 ; 33: 1444-1452$.

16. Sipe JC, Knobler RL, Braheny SL, Rice GPA, Panitch HS, Oldstone MBA. A neurologic rating scale (NRS) for use in multiple sclerosis. Neurology 1984;34:1368-1372.

17. Hirsch RL, Panitch HS, Johnson KP. Lymphocytes from multiple sclerosis patients produce elevated levels of gamma interferon in vitro. J Clin Immunol 1985;5:386-389.

18. Vervliet G, Carton H, Meulepas E, Billiau A. Interferon production by cultured peripheral leukocytes of MS patients. Clin Exp Immunol 1984;58:116-126.

19. Goust JM, Verselis SJ, Shums A. Interferon gamma and interleukin 2 (IL2) production in MS. Abstract. Neurology 1987;37(suppl 1):289.

20. Smith RA, Norris F, Palmer D, Bernhardt L, Wills RJ. Distribution of alpha interferon in serum and cerebrospinal fluid after systemic administration. Clin Pharmacol Ther 1985;37:85-88.

21. Kastrukoff LF, Paty DW. A serial study of peripheral blood T lymphocyte subsets in relapsing-remitting multiple sclerosis. Ann Neurol 1984;15:250-256.

22. Panitch HS, Francis GS, Hooper CJ, Merigan TC, Johnson KP. Serial immunological studies in multiple sclerosis patients treated systemically with human alpha interferon. Ann Neurol 1985;18:434-438.

23. Kelley VE, Fiers W, Strom TB. Cloned human interferon-gamma, but not interferon-beta or -alpha, induces expression of HLA-DR determinants by fetal monocytes and myeloid leukemic cell lines. $J$ Immunol 1984;132:240-245.

24. Sobel RA, Blanchette BW, Bhan AK, Colvin RB. The immunopathology of experimental allergic encephalomyelitis. II. Endothelial cell la increases prior to inflammatory cell infiltration. $J$ Immunol 1984;132:2402-2407.

25. McCarron RM, Spatz M, Kempski O, Hogan RN, Muehl L, McFarlin DE. Interaction between myelin basic protein-sensitized $T$ lymphocytes and murine cerebral vascular endothelial cells. J Immunol 1986;137:3428-3435.

26. Traugott U, Reinherz EL, Raine CS. Multiple sclerosis: distribution of $\mathrm{T}$ cells, $\mathrm{T}$ cell subsets and Ia-positive macrophages in lesions of different ages. J Neuroimmunol 1983;4:201-221.

27. Traugott U, Raine CS. Multiple sclerosis: evidence for antigen presentation in situ by endothelial cells and astrocytes. J Neurol Sci 1985;69:365-370.

28. Hafler DA, Fox DA, Manning ME, Schlossman SF, Reinherz EL, Weiner HL. In vivo activated $T$ lymphocytes in the peripheral blood and cerebrospinal fluid of patients with multiple sclerosis. N Engl J Med 1985;312:1405-1411.

29. Noronha A, Richman DP, Arnason BGW. Multiple sclerosis: activated cells in cerebrospinal fluid in acute exacerbations. Ann Neurol 1985;18:722-725.

30. Sibley WA, Bamford CR, Clark K. Clinical viral infections and multiple sclerosis. Lancet 1985; 1:1313-1315.

31. Waksman BH, Reingold SC. Viral etiology of multiple sclerosis: where does the truth lie? Trends Neuro Sci 1986;9:388-391.

32. Sriram S, Steinman L. Anti I-A antibody suppresses active encephalomyelitis: treatment model for diseases linked to IR genes. J Exp Med 1983;158:1362-1367.

33. Ling PD, Warren MK, Vogel SN. Antagonistic effect of interferon-beta on the interferon-gamma-induced expression of Ia antigen in murine macrophages. J Immunol 1985;135:1857-1863. 


\section{Neurology}

Treatment of multiple sclerosis with gamma interferon: Exacerbations associated with activation of the immune system

Hillel S. Panitch, Robert L. Hirsch, John Schindler, et al.

Neurology 1987;37;1097

DOI 10.1212/WNL.37.7.1097

\section{This information is current as of July 1,1987}

Updated Information \& Services

Citations

Permissions \& Licensing

Reprints including high resolution figures, can be found at: http://n.neurology.org/content/37/7/1097.full

This article has been cited by 40 HighWire-hosted articles: http://n.neurology.org/content/37/7/1097.full\#\#otherarticles

Information about reproducing this article in parts (figures,tables) or in its entirety can be found online at:

http://www.neurology.org/about/about_the_journal\#permissions

Information about ordering reprints can be found online:

http://n.neurology.org/subscribers/advertise

Neurology $®$ is the official journal of the American Academy of Neurology. Published continuously since 1951, it is now a weekly with 48 issues per year. Copyright $(1) 1987$ by the American Academy of Neurology. All rights reserved. Print ISSN: 0028-3878. Online ISSN: 1526-632X.

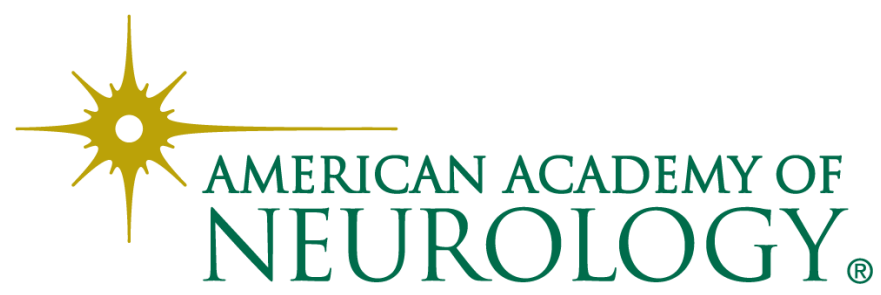

